\title{
MARTIN HEIDEGGER, REINER SCHÜRMANN. DESTRUCCIÓN DE LA TEO-ONTO-ANTROPOLOGÍA Y POST- HUMANISMO*
}

\author{
Martin Heidegger, Reiner Schürmann. Destruction of theo-onto-anthropology and post-humanism \\ Gonzalo Díaz Letelier \\ Universidad de Santiago/Universidad Academia de Humanismo \\ Cristiano/Universidad Metropolitana de Ciencias de la Educación, Santiago, Chile \\ gonz.diaz.letelier@gmail.com
}

\section{Resumen}

El trabajo de Reiner Schürmann sugiere una praxis teórica anárquica y ateológica para pensar la política en la época de la consumación/agotamiento técnico de la metafísica principial: la destrucción de la metafísica política ontoteológica (pars destruens) y la apertura de una politicidad no ontoteológica (pars construens) para habitar de un modo no sacrificial en la época de la anarquía. En este ensayo abordamos la parte destructiva de su analítica, aportando primero algunas indicaciones sobre el desmontaje de la estructura ontoteológica de la metafísica que opera Schürmann a partir de su lectura de Heidegger: su interpretación fenomenológica de la "verdad" como fantasma hegemónico (nómos hermenéutico-normativo fantasmático y excepcional). Luego intentamos exponer la lógica del gobierno implicada en el carácter nómico de la economía política ontoteológica -la conversión del singular/plural en particular/universal- a la luz de una remisión a la metafísica de Aristóteles, específicamente a su doctrina de las categorías y sobre la relación finalísticamente mediada entre potencia y acto. El horizonte de este ensayo es la consideración de una bifurcación ontológico-política en la fenomenología, en relación con la espectralidad, la cuestión del fundamento metafísico principial del habitar y el humanismo que deriva de ello.

Palabras clave: fenomenología, ontoteología, humanismo, fantasma, política, economía, sujeto, presencia, soberanía, gobierno, anarquía.

\begin{abstract}
Reiner Schürmann's work suggests an anarchic and atheological theoretical praxis to think politics at the time of the technical consummation/exhaustion of the principial metaphysics: the destruction of ontotheological political metaphysics (pars destruens) and the opening of non-ontotheological politics (pars construens) to inhabit in a non-sacrificial way in the time of anarchy. In this essay we address the destructive part of his analytic, first providing some indications on the Schürmann's dismantling of the ontotheological structure of metaphysics from his reading of Heidegger: his phenomenological interpretation of "truth" as hegemonic fantasm (phantasmatic and exceptional hermeneutical-normative nómos). Then we attempt to expose the logic of the government involved in

\footnotetext{
* Versión revisada y ampliada de la conferencia presentada en el Coloquio Internacional "Fenomenología y Política" (25 y 26 de abril de 2019), organizado por la Asociación Chilena de Fenomenología, el Grupo de Estudios Trascendentales y el Programa de Doctorado en Filosofía de la Facultad de Filosofía y Humanidades de la Universidad de Chile.
} 
the nomical character of ontotheological political economy -the conversion of the singular/plural in particular/universal- through a reference to Aristotle's metaphysics, specifically to his doctrine of categories and the finalistically mediated relationship between potentiality and actuality. The horizon of this essay is the consideration of a metaphysical-political bifurcation in phenomenology, regarding to spectrality, the question of the principial metaphysical foundation of inhabiting and the humanism that derives from it.

Keywords: phenomenology, ontotheology, humanism, fantasm, politics, economy, subject, presence, sovereignty, government, anarchy.

Fecha de Recepción: 28/05/2019 - Fecha de Aceptación: 22/07/2019

\section{Preámbulo}

Fenomenología y política. Dos términos cuya conjunción se desfigura ahí en el abismo hermenéutico de la existencia en común, antes de cualquier "toma de posición" política. Y es que, así como antes lo habían hecho, entre otras líneas de fuerza, el materialismo atómico griego o el averroísmo árabe-latino, el conatus fenomenológico ha abierto a su modo ese abismo anárquico del mundo, ese abismo hermenéutico que posibilita que haya mundo común precisamente porque "el mundo es aquello que no puede ser convertido en un hogar" (cf. Coccia 51, 52). O dicho de otro modo: justamente porque no hay un mundo es que puede haber mundo común. Pero la fenomenología descubre ese abismo no porque tienda de antemano a alguna especie de cosmopolitismo salvaje, sino porque el asunto más inmediato de sus análisis descriptivos son los suelos y horizontes de sentido que articulan en cada caso nuestro habitar cotidiano, nuestras situaciones hermenéuticas, esto es: los suelos y horizontes de pre-comprensión ontológica e interpretación óntica que articulan nuestro comportamiento práctico y declarativo en el mundo concreto y compartido en que nos toca vivir. La espectralidad de estos suelos y horizontes de sentido se pone en juego, precisamente, como un fundamento sobre el abismo: una tecnología vital, un modo posible en que la vida singular se pone en juego o se estabiliza haciendo mundo en y desde la vida de relación. La fenomenología juega en ese fondo sin fondo. $\mathrm{Y}$ es que en el fondo das Leben ist diesig (la vida es brumosa), recordaba Gadamer que decía Heidegger a sus estudiantes en clases, por allá a comienzos de los años veinte.

Entonces quizás lo virtualmente político de la fenomenología pueda ser la relación de los fenomenólogos con tal espectralidad: esto es, la modalización temporal de su estar en el mundo. Que haya fenomenólogos que exponen las racionalidades devenidas fundamentales del mundo compartido para apropiarlas mediante una comprensión explícita y hallar en ello "autenticidad" y "valor", en términos substanciales o trascendentales. $\mathrm{O}$ que la confrontación fenomenológico- 
crítica con las racionalidades devenidas fundamentales de la época tenga el carácter de un conatus destructivo, materialista e inmanente, desobrante e interruptivo, que se abre al acontecimiento como encuentro y desvío en un time out of joint (tiempo dis-junto) y no en el continuum soberano de una filosofía de la historia trascendental más o menos tácita o expresa. En la caricatura de ambos extremos, corrientemente fetichizados como "tendencias"1 en el campo de la filosofía universitaria y el capitalismo académico, trasluce, sin embargo, lo virtualmente político de la fenomenología como relación temporalizada a la espectralidad. Tiempo e imaginación son, pues, aquí, las claves de este experimento de pensamiento que intento compartir.

Quizás sea preciso en este punto hacer una aclaración de lo que señalamos con el término "espectralidad". Se trata de una dimensión fantasmática y tempórea que hace mundo: es el medio en que la existencia pone en juego su vínculo con el ser, y es rendimiento de la potencia común de la imaginación. No obstante ser la imaginación un medio usable y nunca apropiable, cuando se lo apropia la potencia de la imaginación deviene imagen organizada, el mundo imaginal se torna "imagen del mundo", la multiplicidad singular-plural es reducida a "lo uno" y la potencia común de lo viviente deviene potestad sobre la vida en la curva monstruosa de su violencia excepcional, violencia que agencia la imposición del orden de la representación humanista sobre el supuesto desorden de lo animal. Considerando las indicaciones de Jacques Derrida y Reiner Schürmann, pensamos aquí lo espectral, en relación con su carácter fantasmático y tempóreo, bajo las siguientes determinaciones:

a) en términos fantasmáticos, lo espectral es el obramiento de una fuerza configuradora efectiva de un espacio de juego simbólico que orienta la presenciación -una economía de la presencia y del orden de las cosas, del sentido en que lo que es se muestra como tal. Se trata de una violencia hermenéutica epocal que en cada caso captura la intencionalidad del existente en el estado de una lengua metafísica históricamente dada, organizada principialmente. Tal economía espectral de la presencia sería el correlato de una disposición más o menos permanente de la comprensión y el comportamiento del cuidado de sí en la vida de relación (aquí se juega justamente la cuestión del hábito o habitar, no meramente residencial sino hermenéuticamente pensado). Es decir, la permanencia del espectro hace de la presenciación, de la distinción, conjunción y sucesión de las cosas, ya

\footnotetext{
1 Tales tendencias corresponderían a grandes rasgos a los llamados "heideggerianos de derecha" (énfasis en la apropiación autoafirmante del fundamento existencial co-lectivo) y "heideggerianos de izquierda" (énfasis en la destrucción de la metafísica teo-onto-antropológica y la proliferación anárquica de la vida común).
} 
siempre una re-aparición y una posibilidad fáctica de reconocimiento de sí y de los otros, más o menos anquilosada.

b) en términos fantasmáticos, lo espectral obra "sin ser visto", esto es, como un régimen de perceptibilidad incuestionado como tal (es decir, pre-temático, al modo de un marco invisible de visibilidad).

c) en términos de temporalidad -o en rigor, pensando la espectralidad en relación con la contemporaneidad-, el espectro pertenece a otro tiempo: obra nuestro tiempo en su determinación fáctica - como posibilidad consumada y consumida-, pero no por eso pertenece sólo a su conjunción con un tiempo anterior, pues alberga en su obrar la potencia de un tiempo disjunto, dislocado -como el time out of joint de Hamlet-, un tiempo fuera de quicio que implica apertura, encuentros y desvíos: disyunción del tiempo, brote heterocrónico, un por-venir que no es algo dispuesto para un tiempo posterior (como lo quiere la soberanía vanguardista), sino un yacomo-por-venir en el rizoma de la apertura, el encuentro y el desvío (como acontece en la anarquía de la potencia común).

Considerando lo que antes señalamos como relación temporalizada a la espectralidad, que definiría la virtualidad política de la fenomenología en su performance efectiva, es cierto que la fenomenología "clásica" surgió de un cierto ánimo conservador, que se había venido templando ya fuera frente al arrasamiento vanguardista de las formas tradicionales de "lazo social" por parte del positivismo decimonónico y la democracia liberal capitalista, o frente a la violencia excepcionalista de la revolución nacional-socialista en su pretensión de restituirlos. En ese contexto, el vanguardismo conservador del progresismo o el conservadurismo vanguardista de los revolucionarios nazis, todo ello se cifraba, por ejemplo, en la célebre tensión bipolar entre "comunidad" y "sociedad" (Gemeinschaft und Gesellschaft) (cf. Tönnies 1887), que eran las dos formas que ya había comenzado a adoptar implosiva y expansivamente la norma antropológicometafísica "occidental" -es decir, teo-onto-antropológica- a fines del siglo XIX: en un polo la norma liberal, flexible y mundializante dentro del marco del proyecto civilizatorio de la forma de vida moderna y capitalista; y en el otro polo la norma conservadora, cerrada y territorializada en la autoafirmación identitaria de una tradición evangélica, y/o étnica o nacional. Sin embargo, también podemos pensar en lo que podríamos llamar un cierto potencial an-arquizante de la fenomenología: así lo han hecho una multiplicidad de pensadores, incluso antes que Heidegger y Schürmann, sobre todo desde los años treinta del siglo pasado, familiarizados con la constelación de cuestiones que la fenomenología abrió, pero no necesariamente identificados con su "escuela" -podemos pensar aquí, por ejemplo, en lo decisivas que han sido hasta ahora las problematizaciones del concepto de "comunidad" tal 
como aparecen en los trabajos de Georges Bataille, Walter Benjamin o Hannah Arendt.

Quizás una manera posible de considerar la politización anárquica de la fenomenología sea la performance de una puesta en cuestión radical de la racionalidad occidental como modalización de la tecnicidad humana, al hilo de una consideración de la deriva antropogenética que va, en términos de tecnología vital y su correspondiente modo de producción moderna de mundo, de la destrucción productiva a la devastación (cf. Villalobos-Ruminott 2018). Se podría tratar aquí, por ejemplo, de pensar la articulación teo-onto-antropológica de una excepcionalidad humanista o antropocéntrica como fractura biopolítica entre "lo humano" y "la naturaleza" en general en el curso del Antropoceno, más allá del drama humanoanimal intrahumano que se expresa en la problematización del eurocentrismo y su canonización de la excepcionalidad humana en el espíritu europeo de raíz grecocristiana. La interpretación filosófica de este horizonte antropocénico requiere de un hondo análisis del orden del discurso humanista sobre "la vida", constitutivo de la racionalidad occidental, cuya consistencia epistémica es, como señalábamos, la de una metafísica teo-onto-antropológica: el discurso de un cosmos coronado por un ser supremo (principial, trascendente o trascendental, excepcional) que da la medida de una economía de la presencia (orden de las cosas) en cuyo seno se configura la idea misma de "lo humano" y su mundo (Heidegger 1988 98ss). Un orden del discurso metafísico principial donde el principio mismo (principium, princeps), positividad originaria separada y gobernante, ha transitado progresivamente del Dios al Hombre como instancia soberana -instancia que, a partir de los evangelios de Pablo de Tarso y Juan de Patmos, que piensan al Dios (Padre) como "todopoderoso" ( $\pi \alpha \nu \tau o x \rho \alpha ́ \tau \omega \rho)$, se proyectará con el cristianismo católico romano de corte imperial en la figura filiativa y encarnativa del Cristo Rey (Hijo) como gobernante de todo y sustentador del mundo. Será este dios hecho hombre el que, modernamente, se "secularizará" en la figura del hombre asesino del dios (deicida) y, correspondientemente, en el hombre divinizado -fenómeno pensado por Friedrich Nietzsche (la "muerte de Dios", Gott ist tot) y por Georg Hegel (viernes santo de la razón especulativa protestante) (cf. Nietzsche 1985114 , 115; Hegel 1966433 ss)², y sintomatizado, por ejemplo, en la "religión del hombre" de los positivistas tempranos ${ }^{3}$. La razón moderna nunca canceló el vértice teológico

${ }^{2}$ Cf. del mismo Hegel, un pasaje clave donde refiere al evangelio de Juan (8: 21-33), donde encuentra, a la manera de Lutero, el argumento de Jesús para impugnar el legalismo de los fariseos y señalar hacia la interioridad de la ley en el corazón $(198152,53)$.

${ }^{3}$ Respecto de esta religión positivista de la humanidad que surge tras el declive del hegelianismo, en Chile hay un documento clave para comprender la relación entre la era del hombre y la iglesia universal positivista ("el Amor por principio, y el Orden por base; el Progreso por fin"). Se trata de 
de la metafísica occidental -desde el cual se perfilan la ontología y la antropología: sólo lo "secularizó", poniendo al hombre en el trono vacío dejado por el dios muerto. El hombre autointerpretándose como señor del ser (Heidegger), dominador de la naturaleza como acontecimiento en total -y de la "naturaleza humana" en particular, es decir, del hombre objetivado como objeto de violencia soberana y administración biopolítica 4 . El hombre tomando posición desde sí mismo (como sujeto soberano), frente a la naturaleza (fenomenalizada como objeto y recurso), todo ello en virtud de su poderío técnico de maquinación (Heidegger 1967 26, 27; cf. Díaz Letelier 2012 533-576).

Quizás otra manera posible de considerar la politización anárquica de la fenomenología, esta vez acotando el enfoque, sea la performance de un cierto conatus orientado al desmantelamiento de la metafísica política que, como estructuración hegemónico-sacrificial de la historia, articula una variedad de máquinas soberano-gubernamentales modernas, tanto de derechas como de izquierdas. En el pasaje por tal desmantelamiento de la metafísica política occidental se abre la posibilidad de un cierto "afuera" de la política ontoteológica, una política migrante del afuera, que se desarticule tanto respecto de la metafísica del sujeto como de la metafísica de la presencia. Pero la apertura de tal posibilidad exige pensar las condiciones de existencia en la época de la consumación moderna de la metafísica ontoteológica, la configuración esencial de las políticas y economías que hegemónicamente configuran hoy los mundos sociales y culturales, los agenciamientos y relacionamientos, el trabajo, la vida y la muerte. Resuenan aquí, claro está, los pensamientos de Martin Heidegger y Reiner Schürmann, o la lectura que hace Schürmann de Heidegger, en la medida en que lo que se trata de poner en juego es una reflexión ateológica y anárquica sobre la puesta en juego del estar en el mundo en común, en tensión con las formas de comprender y ejercer el poder como soberanía teológico-política y gubernamentalidad equivalencial (Nancy 2012). La posibilidad de tal reflexión ateológica y anárquica se abre en medio del desierto del nihilismo contemporáneo, que es el desierto de la consumación tecno-económica de la metafísica, con su maquinación total y flexible de lo ente de acuerdo a cálculo -consumación que es al mismo tiempo su agotamiento, por obrar un principio incondicionado de razón suficiente que erosiona toda idealidad mediante el despliegue arcóntico del cálculo desembozado. Se trata de una flexibilidad que arrasa con la principialidad ontoteológica al mismo tiempo que la realiza de un modo incontinente,

un texto escrito por Luis Lagarrigue, "discípulo" chileno del "supremo maestro" francés Auguste Comte (cf. Lagarrigue 1946 ("año 92 de la Era Positivista" [sic]).

${ }^{4}$ Cf. Karmy, Rodrigo. Políticas de la excarnación. Para una genealogía teológica de la biopolítica. Editorial UNIPE: Buenos Aires, 2014. 
precisamente en virtud del vaciamiento o desfondamiento de su propia principialidad: tránsito de la idealidad condicionante al cálculo incondicionado y la proliferación espectacular de imágenes como modulación fundamental del medio imaginal. En términos de práctica teórica de la política anárquica, lo que estaría en juego es una labor destructiva de la metafísica ético-política de raíz greco-cristiana, que buscaría, como su momento afirmativo, abrir la diferencia radical de la política, esto es, pensar otro modo de la política, una política no enmarcada por la metafísica teo-onto-antropológica. Una diferencia que, a la luz de nuestro presente, no acontece radicalmente ni en la política de derechas ni en la de izquierdas.

Sería interesante proyectar, entonces, al menos un par de cuestiones que nos podrían dar ciertas indicaciones sobre la praxis teórica anárquica y ateológica que sugiere el trabajo de Reiner Schürmann para pensar la política: respecto de su pars destruens, la destrucción de la metafísica política ontoteológica; respecto de su pars construens, la praxis teórica de una politicidad no ontoteológica. Aquí abordamos preliminarmente algunos aspectos de la pars destruens o de desmontaje de la metafísica política ontoteológica, aspectos relativos a la economía de la presencia y la estructura de su lógica de gobierno ${ }^{5}$.

\section{Ateología y anarquía ontológica}

En su momento destructivo, la posibilidad de una politicidad no ontoteológica implica pensar la relación entre vida, metafísica y poder. Esbozar algo así como una consideración materialista de las estructuras básicas de la imaginación política y económica que operan la articulación de las formas históricas de soberanía y gobierno en Occidente. Se trataría de investigar en una dirección no espiritualista ciertos espectros que tienen una fuerza configuradora efectiva de lo social, fetiches imaginales cuya fuerza organiza aspectos básicos de sus horizontes de sentido más sedimentados, es decir, de sus prácticas discursivas e institucionales.

Aquí una deconstrucción de la imaginación político-económica occidental consistiría en la exposición de su fetiche estructural más arraigado, a saber, el arcano nómico, históricamente gestado y modulado, de una estructura crucial cuyos polos aquí localizamos bajo las rúbricas modernas de soberanía y equivalencia. Se trataría, quizás, de un ejercicio preliminar de la potencia del pensamiento común para interrumpir los efectos de captura de la vida bajo la égida de una tradición

\footnotetext{
${ }_{5}^{5}$ Para un desarrollo más sistemático de estas cuestiones, remito aquí a mi ensayo "Ontoteología, economía de la presencia y lógica del gobierno: una lectura de Reiner Schürmann", Revista Política Común (dossier “On Reiner Schürmann”, coordinado por Alberto Moreiras) (2017): s/p.
} 
metafísica como la que está aquí en cuestión. La tradición metafísica ontoteológica en cuestión implica una filosofía de la historia que, concebida evolutivamente en diversas discursividades, avanza autoafirmándose como progreso sacrificial (evangelización, civilización, democracia capitalista) sobre la barbarie animal de las formas de vida "atrasadas", "desviadas" o "rebeldes": una filosofía de la historia cuya fatalidad sería preciso desactivar puesto que, autoafirmando su vigor en una incuestionada y transparente obviedad -performada mediante violencias físicas y simbólicas que disponen del hábito en los usos del cuerpo y la imaginación-, ella define radicalmente las posibilidades y los límites de nuestra facticidad, determinando los perfiles de la norma antropológica de una vida ascendente (biopolítica, en los sentidos desarrollados por Foucault y Agamben) y sus reversos reactivos o predadores de política sacrificial (necropolítica, según el concepto acuñado por Achille Mbembe). Se trata de hacer visibles las estructuras imaginales metafísico-performativas que organizan y apropian la potencia común de la imaginación, deviniendo así el fundamento de la potestad principial que captura la proyección orientativa de lo colectivo en formaciones de dispositivo soberanogubernamentales que, a la par de productivizar la vida proyectándola y promoviéndola en un "sentido ascendente", espiritualizan y operativizan la catástrofe contemporánea de la vida en su dimensión sacrificial y sacrificable.

Según Heidegger, la historia de la filosofía occidental es la historia de la metafísica, que en cuanto se afirma en su estructura ontoteológica, es asimismo la historia del "olvido del ser": la historia de una configuración hegemónica y dinámica de la imaginación que se autoafirma en la fundación como posición del fundamento existencial colectivo, eclipsando el abismo del ser como posibilidad infinita abierta desde la facticidad -el abismo del ser (Abgrund), la negatividad originaria (das Nichts, la nada) que se expresa en la heterocrónica e irreductible multiplicidad efectiva y posible de lo ente. En otras palabras, se trata de una metafísica que olvida la abismal diferencia ontológica entre ser y ente -y por tanto el abismo del ser desde el que se constela lo ente- al comprender eminentemente el ser en sentido fundacional-fundamental como un ente fantasmático (Dios, naturaleza, sujeto-consciencia) originante y gobernante de la presencia. Esta metafísica se articula así a partir de lo que llamaremos la "diferencia ontoteológica", que implica el "olvido del abismo del ser". Se trata de una comprensión del ser que, a modo de a priori fáctico hermenéutico, encamina la interpretación del ente y, por tanto, el trato práctico y declarativo con lo ente -con lo otro y los otros-desde una correlativa resolución del sí-mismo (subjetivación). Se trata de una metafísica principial, una metafísica de la (auto)posición fundante y de la reflexión esencializante sobre el fundamento puesto desde la prepotencia de una pre-tendida positividad originaria. Heidegger lo formula, algo oracularmente, en el siguiente pasaje: 
La $\dot{\alpha} \lambda \dot{\eta}^{\prime} \vartheta \varepsilon \iota \alpha$-apenas esenciante y no retrocediendo al inicio, sino progresando al mero desocultamiento- viene a caer bajo el yugo de la i $\delta \varepsilon ́ \alpha$ (Heidegger 2000 458).

El pasaje, referido al hito platónico, remite a la economía de la presencia que deriva de toda metafísica teológica del sujeto: la verdad cae bajo el yugo de la idea que reduce la multiplicidad del acontecimiento a lo uno de un orden hipostasiado, "olvidando" así el abismo del ser, la historicidad radical de lo múltiple y heterogéneo en su potencia, progresando más bien al puro y seguro resplandor de la plena presencia monocrónica, normalizadora y sacrificial de los mundos de la vida inscritos en la historia de la metafísica ontoteológica. Es la existencia, en lo que determina más radicalmente su habitar -el logos interpretativo ( $\lambda$ ó

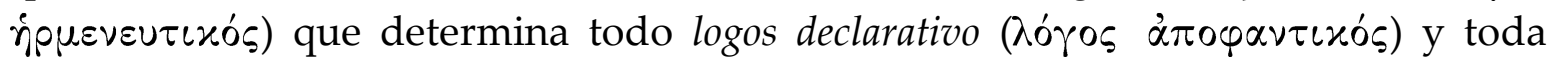
acción $(\pi \rho \tilde{\alpha} \xi \iota \varsigma)$ y producción $(\pi \circ i \eta \sigma \iota \varsigma)$ (cf. Aristóteles 1965) ${ }^{6}$ la verdad o $\alpha \lambda \eta^{\prime} \vartheta \varepsilon \iota \alpha$ en sentido griego) - la que cae en cada caso bajo el yugo del interdicto hermenéutico ontoteológico y su normatividad. Cosmética policial como captura de la imagen y movilidad de lo viviente, a la vez que sacrificialidad del movimiento discordante de lo que no se acoge, difiere o no alcanza a la norma de lo que "es" propiamente tal: de lo que propiamente es, decimos, de acuerdo al vigor (fuerza) y vigencia (valor de norma) de la facticidad de un orden discursivo e institucional trascendentalizado y hegemónico.

Ya sea en el viejo modo de la principialidad metafísica idealista de corte platónico-cristiano (la veritas como adaequatio intellectus ad rem), o en el de su deriva en la moderna subjetividad soberana con la certeza matemática de su representación y cálculo, se trata de la disposición del estar en el mundo en común desde un principio de razón suficiente (nihil est sine ratione) que en cada caso está dotado de una estructura ónticamente determinada, constituida por un ente supremo y excepcional que da jerárquicamente la medida (Dios, naturaleza, consciencia) y una a tal gracia correspondiente economía de la presencia (orden divino, orden natural u orden antropocéntrico del mundo), economía que norma el sentido de la presencia y de la sacrificialidad: una economía que normaliza la vida y la muerte.

Nuestro presente, en la interpretación de Heidegger, sería el de la época de la consumación de la metafísica, que al mismo tiempo es la de su agotamiento. La consumación y agotamiento de esta metafísica ontoteológica o principial se expresaría en el nihilismo. El modo de ser originario de la existencia que es la técnica (la tecnicidad originaria como modo de poner en juego el vínculo existencial con lo ente) desplegado en su forma moderna ("cartesiana", esto es, como

\footnotetext{
${ }^{6}$ Hay varias traducciones - partiendo de la latina «De Interpretatione»- y el texto forma parte del escolarmente llamado «Organon» ('Opravov).
} 
subjetividad soberana en la certeza matemática de su representación) ha llegado a operar desde un principio de razón suficiente que se ha vaciado o desfondado (sin Dios trascendente, sin naturaleza hipostasiada, sin subjetividad como tribunal absoluto), deviniendo así principio nihilizado como puro cálculo incondicionado productivización capitalista de la vida que habitamos en el orden de una religión sin dogma (para citar a Walter Benjamin): tecnología dispositiva de un patrón de acumulación totalitario (consumación principial, razón imperial excepcionalista), pero a la vez flexible (agotamiento principial, desfondamiento nihilista de su contenido positivo y, por tanto, de su determinación veritativa en sentido fuerte, que es sustituida por la dinámica del cálculo incondicionado, el gobierno de la imagen telemediática y la así determinada efectivización y productivización de las cosas vivas e inertes).

Sin embargo, y precisamente por ello, ésta es la época en que la consumación/agotamiento de la metafísica ontoteológica abre la posibilidad de la anarquía como fin de la metafísica política productivizante y sacrificial -suscitando nuevamente la pregunta por el abismo del ser (y la posibilidad infinita de lo social desde la desnaturalización de su orden fáctico trascendentalizado, impuesto y automatizado), por la vía de la desactivación del principio de razón suficiente en su operación arcóntica, principio que hace posible operar toda fundación y fundamento eclipsando así lo abismal de la existencia en común en el mundo -der Abgrund, el sin-fundamento de la vida cual sea en la diferencia del mundo con los otros: el sin-fundamento que la existencia, en su modulación occidental, conjura metafísicamente para poder establecerse, autoafirmarse, habitar y progresar en sentido ontoteológico.

Reiner Schürmann, pensador clave para pensar esta cuestión, a partir de su lectura de Heidegger sostiene que, en su articulación efectiva, el imperar "occidental" se ha autoafirmado históricamente en una serie o montaje discursivo (ensamble no necesariamente lineal: paralelas, yuxtaposiciones y procesos de mutación y traducción) de "constelaciones de presenciación" dominadas por principios epocales de comprensión ontoteológica de ser y tiempo y la consiguiente interpretación, normativización y trato de lo ente. Los hitos de esta deriva, según Schürmann, han sido el "giro socrático" y el "giro tecnológico", es decir: la metafísica idealista y su consumación técnica, que como veremos de alguna manera coinciden con las matrices metafísico-políticas de soberanía y gobierno en su deriva de filiación y progresivo ensamble.

En el tono anímico de Schürmann el pensamiento es, cimbrándose en el fondo sin fondo de la existencia en lo abierto, abismamiento. En el incipit de su libro «Des hégémonies brisées» (1996), Schürmann dice que: 
Pensar es demorarse en las condiciones en las que uno está viviendo, detenerse a considerar el sitio en el que vivimos. Pensar es un privilegio de nuestra época, para la que se vuelve evidente la esencial fragilidad de los referentes soberanos. Esto asigna a la filosofía, o a lo que sea que tome su lugar, la tarea de mostrar la condición trágica que subyace a toda construcción principial (2003 3)7.

La filosofía -o, como habría que mostrar, la potencia de un pensamiento no enmarcado en la función filosófica "profesional" o "universitaria"- habría de intentar desmontar las condiciones "epocales" de nuestro habitar, abriendo así el abismo del ser como posibilidad infinita desde la facticidad. Pensar es abrir el abismo de la época. Pero ¿qué es una época? Schürmann define una "época" como una organización fantasmática instituida por el lenguaje (2003 4). Schürmann evoca al

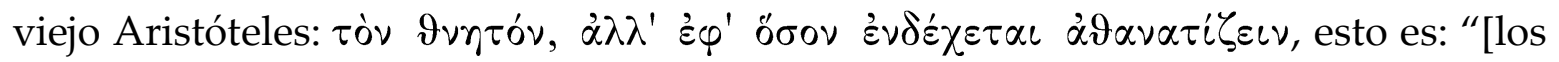
hombres son] mortales, pero en la medida en que les es posible se inmortalizan" (Aristóteles 1994 1177b3) . Y a propósito de tal “inmortalización" como conjura de la finitud puesta y sedimentada metafísico-políticamente como "fantasmática hegemónica", sostiene que:

Primero hay una atracción tética inmortalizante, luego la retirada que nos singulariza. Si quiere cuidarse de enredos subjetivistas, esta analítica tendrá que trabajar en sitios históricamente dados. Tendrá que relacionarse con una topología de las hegemonías rotas, una topología que analiza las constelaciones nómicas a las que aquellas hegemonías han dado nacimiento (Schürmann 2003 6).

La labor de una destrucción de la metafísica, como vemos, se traduce en Schürmann a la modalidad de una analítica de los fantasmas hegemónicos (hegemonic fantasms), de sus montajes y estabilizaciones epocales, de sus rupturas y modulaciones históricas. Schürmann se concentra en la deriva imperial de tres

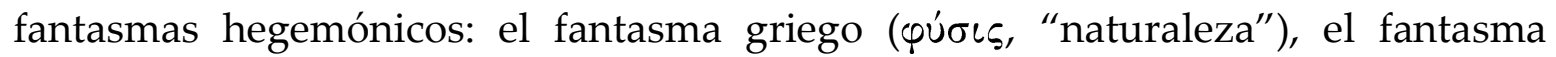
latino (Deus-natura) y el fantasma moderno (subiectum-consciencia), que en cada caso desocultan la diferencia radical del ser, pero aprehendida nómicamente por la fuerza hermenéutica y normativa que la clasifica y jerarquiza sacrificialmente. Se trataría de una analítica de los principios epocales (fantasmas hegemónicos excepcionales: diferencia ontoteológica) y sus economías o "constelaciones de presenciación (Anwesung)", constelaciones nómicas que norman los regímenes

\footnotetext{
7 Traduzco al español este y otros pasajes desde la versión en inglés de este libro: Schürmann, Reiner. Broken hegemonies, vol. I, traducción del francés al inglés Reginald Lilly. Indiana University Press, Bloomington:Indianapolis, 2003. Respecto de la condición trágica de la existencia, cf.. Schürmann, Reiner. "Tragic differing: The law of the One and the law of contraries in Parmenides". Graduate Faculty Philosophy Journal 13/1 (1988): 3-20.

${ }^{8}$ La traducción del griego al español de esta cita y de todas las que aparecen a lo largo del presente texto yo las he elaborado.
} 
clasificatorio/jerarquizantes de la presencia en la medida en que articulan una temporalidad y una espacialización hegemónicas (Schürmann 2003 6).

El fantasma hegemónico (hegemonic fantasm) es un trascendental monológico y monocrónico autofirmado como tal, que orienta de antemano los horizontes de sentido del comportamiento práctico y declarativo de un modo pre-temático, hasta sedimentar en la ley positiva. Schürmann ejemplifica esta formulación refiriéndose al fantasma hegemónico latino natura:

Tomemos como ejemplo la "naturaleza" en virtud de la cual los moralistas latinos medían todas las cosas. Significaba una continuidad del orden que primero unía las partes del alma, luego ligaba al individuo a la ciudad y a los demás hombres, y finalmente vinculaba el mundo visible a los dioses. [...]. Al actuar "contra la naturaleza" (contra natura) uno evidentemente no está yendo contra un ente, contra una cosa que existe fuera del lenguaje. Más bien, uno está atacando una maximización puesta en el lenguaje, una realidad que no entra en la experiencia del mundo, pero que sin embargo nos señala qué hay que hacer y qué no hay que hacer. Maximizar una unidad lingüística es "aumentar" su poder de significación, y por tanto investirla de "autoridad" -en latín auctoritas deriva de augere, lo que en su aumento deja crecer y orienta tal crecimiento. Los sodomitas eran quemados en el nombre de la naturaleza (10).

El fantasma hegemónico es "fantasmático" por su trascendencia lingüística respecto de lo óntico cuya presenciación gobierna hermenéutica y normativamente (diferencia ontoteológica): el fantasma es infundado y autofundante sobre el abismo del ser. El fantasma hegemónico es "hegemónico" porque, si bien es infundado ${ }^{9}$, opera como fundante: se articula como determinada pre-comprensión del ser (nivel ontológico: la $\alpha \lambda \eta^{\prime} \vartheta \varepsilon \iota \alpha$ o verdad como figura histórica del desocultamiento del ser como ente con sentido) que encamina epocalmente de antemano (a priori fáctico) la interpretación del ente -su percepción y apreciación(nivel óntico), orientando así en cada caso la ejecución de la existencia en su comportamiento práctico y declarativo respecto de sí mismo, los demás vivientes y las cosas. Finalmente, el fantasma hegemónico es "epocal" porque organiza constelaciones mundanales imperiales -el mundo greco-romano imperial; el mundo de la unidad de la cristiandad católico-romana; el mundo de la civilización cristiano-capitalista. La imperialidad epocal del fantasma hegemónico se articula en función de su carácter autofundante (performatividad de una pretendida positividad originaria), monológico y monocrónico, lo que implica la negación de su afuera (es expansivo, imperial-colonial y sacrificial):

\footnotetext{
${ }^{9}$ El fantasma hegemónico es infundado porque se pone como positividad originaria, eclipsando su fundamento negativo, conjurando el abismo de sublimidad del ser -la $\lambda \hat{\eta} \vartheta \eta$, el ocultamiento o sinsentido radical del ser, la posibilidad infinita de sentido- o la radical diferencia y multiplicidad de lo ente sobre la cual se pone.
} 
Yo describo un fantasma hegemónico como un referente que significa una obligación -ligadura, ligazón- que tenemos con respecto a la cual no hay un afuera (Schürmann 2003 10).

Las figuras de la $\alpha \lambda \eta^{\prime} \vartheta \varepsilon \iota \alpha / v e r i t a s$ en el sentido metafísico greco-cristiano y su deriva moderna son, pues, los llamados por Schürmann “fantasmas hegemónicos". El fantasma hegemónico es ontoteológico (incondicionado/condicionante) y excepcional (lo reunidor que trama el mundo de la vida, operando como un trascendental -non res-desde un fundamento negativo). Schürmann:

La historia de los fantasmas hegemónicos es la historia de los referentes últimos, que son, literalmente, "nada", non res. [...] Un referente relacional que no aparece entre los entes. La doctrina de los principios trata de estas autoridades últimas. Una función última es relevante en principio, toda vez que permite todo lo que somos capaces de decir, hacer y saber bajo su égida (8).

Y más adelante:

Es imposible describir [al fantasma hegemónico] del mismo modo en que se describe a un ente: se trata más bien de mostrar el modo de operación de algo así como un punto epocalmente variante al cual todos los entes deben ser referidos si han de tener sentido. Como término de relaciones normativas, tal centro es la "realidad" última que hace concebibles a los singulares dados y en la que sus singularidades son subsumidas. El fantasma hegemónico le impone a las singularidades una archi-violencia. Violencia arcana, porque lo que se pone como realidad última no podría ponerse como tal si no subsumiera en su elemento a todo lo que puede llegar a ser fenómeno (id. 9).

Schürmann, leyendo a Heidegger en clave anárquica, sitúa en el horizonte y avanza significativamente la titánica tarea de una fenomenología de los principios epocales -y de sus correspondientes discursividades ("léxicos" nómicos, interdictos hermenéuticos y normativos de la doxa y de los usos y relacionamientos de los cuerpos) e instituciones (que operativizan la captura de los cuerpos y la imaginación en una economía de la presencia y, particularmente, en un régimen de producción de lo humano)- en el sentido de su desmontaje o destrucción (Abbau o Destruktion, en los términos técnicos de Husserl y Heidegger respectivamente). Es decir, en lugar de pensar meramente la existencia fáctica en su condición de inscrita y sólo inscrita en la economía epocal principial que define la productivización de su ser en el seno del dispositivo o ensamble discursivoinstitucional -y aquí resuenan tanto la Gestell de Heidegger como el dispositif de Foucault-, Schürmann pregunta asimismo por la práctica del estar en el mundo con otros bajo la rúbrica de un "pensamiento atento al ser como tiempo en una posibilidad an-árquica", o por la "posibilidad de una economía an-árquica en el fin de la metafísica occidental"10. Por ahora convendrá subrayar que esta tensión entre la

10 Muñoz, Gerardo. "Das Leben ist ohne warum: una nota sobre Reiner Schürman”, en sitio electrónico Machina et Subversio Machinae, entrada del 7 de febrero de 2016: s/p. Schürmann 
imperialidad principial histórico-epocal y la potencia de la existencia en común se exhibe hoy, paradojalmente, como irrupción de un pensamiento anárquico o interruptivo de la tecnología gubernamental en plena consumación de la época técnica -es decir, de la época de la gubernamentalización total.

Antes señalábamos que, de acuerdo a Schürmann, el "giro socrático" (metafísica del sujeto y la presencia) y el "giro tecnológico" (consumación técnica de tal metafísica) de alguna manera coinciden con las viejas matrices metafísicopolíticas de soberanía (teología política) y gobierno (gubernamentalidad económica) en su deriva de filiación y progresivo ensamble operativo en el dispositivo occidental contemporáneo que se autoafirma como tal. Al respecto hay una advertencia que tomar en cuenta, al hilo de una crítica de Giorgio Agamben a Schürmann:

El término arche significa en griego tanto "origen" como "comando". A este doble significado del término corresponde el hecho de que, tanto en nuestra tradición filosófica como en la religiosa, el origen es lo que desde el inicio expone en el ser, y no solamente como un exordio que comparece y deja de actuar en aquello a lo que ha dado vida, sino también como lo que comanda y gobierna su crecimiento, desarrollo, circulación y transmisión -en una palabra, la historia. En un libro importante, «II principio d'anarchia» (1982), Reiner Schürmann ha tratado de deconstruir este dispositivo, a partir de una interpretación del pensamiento de Heidegger. Él distingue en el último Heidegger el ser como puro venir a la presencia y el ser como principio de la economía históricoepocal. A diferencia de Proudhon y de Bakunin, que no han hecho más que "mover el origen" sustituyendo al principio de autoridad por un principio racional, Heidegger habría pensado un principio anárquico, en el cual el origen como venir a presencia se emancipa de la máquina de las economías epocales y no gobierna más el devenir histórico. El límite de la interpretación de Schürmann aparece con evidencia en el mismo sintagma, queridamente paradojal, que da el título al libro: el "principio de anarquía". No basta separar origen y comando, principium y princeps: como habíamos mostrado en "II Regno e la Gloria», un Rey que reina pero no gobierna no es más que uno de los polos del dispositivo gubernamental, y volver un polo contra otro no es suficiente para detener su funcionamiento. La anarquía no puede estar en la afirmación de principio: ella sólo

sostiene que en pleno giro tecnológico irrumpe un pensamiento que abre una ética y una politicidad anárquica, esto es, aprincipial: “(...) la genealogía de los principios mostrará cómo nació este linaje; cómo, con un cierto giro radical, el giro socrático, las constelaciones de presenciación comenzaron a ser dominadas por principios; cómo, por último, con otro giro no menos radical que se anuncia en el giro tecnológico, estas constelaciones pueden dejar de ser dominadas por principios. Pero este pensamiento de una posible extinción de los principios se fue articulando progresivamente en Heidegger. Ha quedado claro desde el comienzo que la pregunta: '¿Cuándo va a escribir usted una ética?', pregunta que se le planteó tras la publicación de su obra Sein und Zeit, surgió de un malentendido. Pero es sólo en los últimos escritos de Heidegger que la cuestión de la acción encuentra su contexto adecuado: la genealogía de una línea finita de principios epocales" (Schürmann, Reiner. Heidegger on Being and Acting: From Principles to Anarchy, trad. francés al inglés Christine Gros. Indiana University Press: Bloomington, 1986. 11 [cf. Muñoz 2016]; la traducción del inglés al español es mía). 
puede liberarse como un contacto, ahí donde tanto el arche en tanto origen como el arche en tanto comando son expuestos en su no-relación y neutralizados ${ }^{11}$.

Es preciso poner en cuestión la lógica soberano-principial si se va a poner en cuestión la lógica económica de los aparatos hegemónicos de tecnificación y productivización de la vida. Lo que hay que pensar en la ocasión que nos toca no es una gubernamentalidad económica que ha desplazado a la soberanía política, sino más bien la nueva modalización como se articulan tales arcanos en la forma de la subsunción contemporánea de la política en la economía. En este pasaje clave, Agamben remite a los sentidos consagrados del término griego arché ( $\alpha \rho \chi \eta)$ : origen (principium) y comando (princeps) -sentidos "consagrados" por una tradición filosófica y religiosa europea que opera como dimensión arqueológica desde la que se autoafirma la política occidental. El origen (principium) y el comando (princeps) nombran así los dos polos del dispositivo occidental: soberanía y gobierno, política y economía (Agamben: "un Rey que reina pero no gobierna no es más que uno de los polos del dispositivo"). En su deriva de inmanentización pastoralgubernamental, la forma soberanía funciona dejando y haciendo vivir $-\mathrm{y}$ haciendo y dejando morir- gobernando el ser y el tiempo del viviente: la potencia de su cuerpo, su movilidad e imaginación, su inscripción en un determinado esquematismo del tiempo. De manera que la soberanía política productiviza una economía de lo viviente y así gobierna orientando el avance de la "Historia".

Precisamente atendemos aquí a esa copertenencia de los polos, en cuanto funcionalidad de la máquina soberano-gubernamental articulada por la lógica y los imaginarios de la estructura crucial theos/arché. Ya en la metafísica griega antigua -

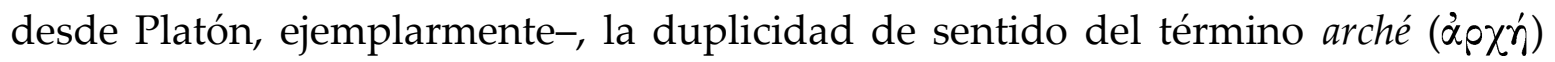
conecta íntimamente a este término con otro: theos ( $\vartheta \varepsilon o ́ s)$. Tal arcano metafísico se expresa en el canon de la filosofía primera que lo explicita en la discursividad dúplice de teología y ontología. Lo fundante (origen, principium) que inicia el movimiento a la presencia y el fundamento (comando, princeps) que se pone en obra gobernando la presenciación y movilidad de los entes. Tal es la estructura "ontoteológica" de la metafísica expuesta por Heidegger, en su aspecto más general: verticalmente una teología de lo fundante ( $\vartheta$ sós, poder fundante y causa sui);

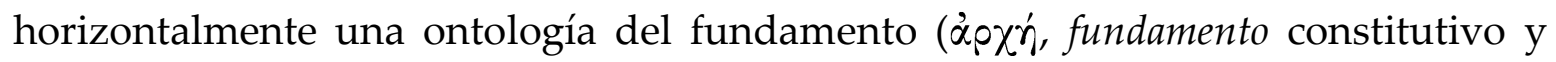
teleológico común a todo lo ente). Tal metafísica anida un pensamiento simple sobre poder y ser: piensa lo que da la medida del venir a presencia. Se trata de pensar la copertenencia entre lo que da la medida (soberanía política) y lo que viene a presencia en una determinada medida (gobierno económico). El poder

\footnotetext{
${ }^{11}$ Agamben, Giorgio. L'uso dei corpi. Neri Pozza Editori: Vicenza, 2014 (cf. Muñoz 2016; traducción del italiano al español es mía).
} 
comprendido como potestad productivizante sobre el ser (Deus) en la temporalidad de la progresiva "puesta en obra" (opus).

La necesidad de pensar los dos polos de la maquina soberanogubernamental y sus modalizaciones en la escena material de la historia obedece a una constatación preliminar: no es posible realizar un "vuelco" radical en la

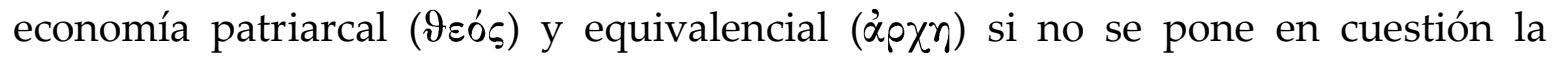
estructura ontoteológica que articula metafísicamente a la política occidental que se autoafirma como tal. Desde aquí se puede atisbar en un sentido esencial la advertencia de Agamben, que formularíamos aquí como sigue: la posibilidad de una economía anárquica que emancipe a la vida de su produtivización soberana implica deconstruir el ensamble entre los dos polos de la racionalidad económicopolítica occidental, camino que habría sido desbrozado por Heidegger al pensar "el origen como venir a presencia que se emancipa de la máquina de las economías epocales y no gobierna más el devenir histórico" (cf. Muñoz 2016). En esta dirección se entiende, por ejemplo, la referencia crítica de Agamben a los planteamientos de anarquistas clásicos como Pierre-Joseph Proudhon y Mijail Bakunin, que habrían sólo "movido el origen", sustituyendo al principio de autoridad por un principio racional -como también lo hicieron Henri de SaintSimon o August Comte, haciendo de este modo parte de la inteligencia filosófica y científico-social que de diversas maneras ha abastecido la deriva tecnocrática que expresa la subsunción tecno-económica de la política.

Nuestra hipótesis provisional de lectura es que la metafísica teo-ontoantropo-lógica se articula como una estructura crucial cuyos ejes son los arcanos político y económico: soberanía excepcionalista y gobierno equivalencial. Y que estos dos arcanos operarían juntos la estructura de un patrón de acumulación y una tecnología de crianza -el humanismo. De modo que una crítica de la ontoteología no haría sino desnudar a esta metafísica como la matriz fantasmática del patrón de acumulación en todos sus aspectos materiales: en la crítica de los dos arcanos se tendría que hacer inteligible la posibilidad de una crítica del patrón de acumulación en sentido político, económico, estético, semántico y moral, aspectos que en su conjunto definirían la orientación productiva de "lo humano". Si la estructura crucial de la ontoteología no es pensable sino sobre el fondo de la metafísica del sujeto (teología política) y la metafísica de la presencia (ontología, economía de la presencia), lo que está en juego es precisamente el juego de tensiones entre imaginación e imagen -políticas de la imaginación y economías de la imagen-, o dicho en otro registro, la relación entre autoridad y régimen de producción: se trata de otra forma de pensar el doble vinculo de la vida con el poder, el vínculo político y económico de la vida con el poder. Ante todo nos interesa aquí el vínculo de la vida con el poder con que se expresa la metafísica del 
sujeto en la performance de la soberanía: nuestro asunto primario es la ficción imaginal de la trascendencia del poder soberano y su proyección económicogubernamental en la inmanencia como captura, productivización y modelamiento de la vida -tecnología de crianza humanista.

De modo que pensar el vínculo entre vida, metafísica y poder significa aquí pensar la potencia común de la vida en juego y su captura por la violencia formadora de sus propios espectros soberano-gubernamentales. Para pensar esto resulta interesante conectar nuestro intento con la crítica que hace Agamben a la

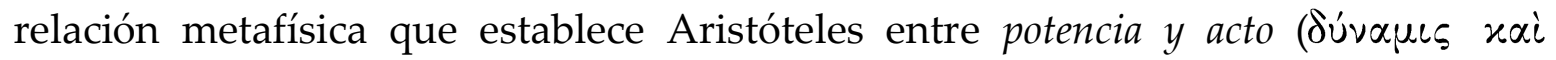
éppov) y, a su vez, con el problema de la relación entre imaginación e imagen -en la medida en que el acto determinado arqueoteleológicamente es análogo a la imagen organizada $^{12}$. Lo que se juega en esta exposición del vínculo entre vida, metafísica y poder es, por consiguiente, una variedad de la crítica a la ontoteología fotológica que despunta y predomina desde Platón, entendiendo el sello fotológico como la clausura de la potencia de la imaginación en la facticidad de la imagen: el "ser verdadero", la esencia, que históricamente ha devenido desde la forma rígida de la idea teológico-metafísica hasta las formas flexibles de la representación tecno-científica y el espectáculo mediático. Se trata de desarmar el "mito de la caverna" y la captura gubernamental de la infancia (potencia) implicada en su "pedagogía" $(\pi \alpha \iota \delta \alpha \gamma \omega \gamma(\alpha)$, mito fundamentalmente heliocéntrico en la medida en que la idealidad (imagen ontológica del mundo y su orden solar, teológicamente fundado) captura la potencia de los vivientes mediante la producción de una relación "mimética" entre el viviente y el ser ideal que da la medida de su deuda y la meta teleológica de su perfección. En un movimiento que va de la relación extática a la relación interiorizante del viviente con el ser-verdadero, la mímesis de la metafísica platónica sería un antecedente griego de lo que después será

\footnotetext{
${ }^{12}$ La cuestión de la imagen aparece, en trabajos como los de Jacques Rancière o Georges DidiHuberman, al hilo de la tensión entre "imagen pensativa" (que desconcierta o desorganiza la imaginación) e "imagen montaje" (que fetichiza u organiza la imaginación). Así lo ilustra DidiHuberman: “(...) si lo que está mirando sólo le hace pensar en clichés lingüísticos, entonces está ante un cliché visual y no ante una experiencia fotográfica. $\mathrm{Si}$, por el contrario, se encuentra ante una experiencia de este tipo, la legibilidad de las imágenes ya no está dada de antemano, puesto que se halla privada de sus clichés, de sus costumbres: primero supondrá suspenso, la mudez provisoria ante un objeto visual que le deja desconcertado, desposeído de su capacidad para darle sentido, incluso para describirlo; luego, impondrá la construcción de ese silencio en un trabajo de lenguaje capaz de operar una crítica de sus propios clichés. Una imagen bien mirada sería, entonces, una imagen que ha sabido desconcertar y después renovar nuestro lenguaje y por lo tanto nuestro pensamiento" (Didi-Huberman, Georges 2007. 31; cf. Villalobos-Ruminott 2013 16). Ver también, para poner en conexión esta cuestión con la de la discursividad de la filosofía de la historia, Thayer, Willy. "Raúl Ruiz: imagen estilema”, Revista de Filosofía Otro Siglo 1/ 2 (2017): 03-46.
} 
concebido en la teología cristiana como encarnación y, modernamente, como subjetivación.

La diferencia ontoteológica -como posición principial que "olvida" el abismo de la diferencia ontológica entre ser y ente, entre potencia y facticidad- se expresa, siguiendo al fenomenólogo Schürmann, como un fantasma hegemónico que articula la "secreta actividad sintética del sujeto" -síntesis de acuerdo a un principio o vóuos que abre un orden simbólico:

Un sentido fundamental del ser es siempre el resultado de una tesis nominativo-normativa que atrae a los fenómenos a un foco, un sentido relacional al que los griegos llamaron "relación a lo uno" ( $\pi$ pós हैv), que Cicerón aplicó a la naturaleza ("ad naturam referebas omnia") y que, a su modo, fue retenido por el proyecto contemporáneo de una arqueología del saber que problematiza "esa forma de historia que fue secreta pero enteramente relacionada a la actividad sintética del sujeto" [Foucault]. / Una referencia a esto está en obra en el interior mismo de ese orden simbólico que Nietzsche desafiaba a los sobrios realistas eliminar del singular. En orden a constituir la fenomenalidad de los fenómenos, en orden a universalizarlos, un orden representacional debe organizarse alrededor de un principio, un referente fantasmático que dé la medida de toda representación. Un fantasma hegemónico así concebido no sólo nos orienta a referirlo todo a él, sino que además pone un suplemento interminable de significaciones, es decir, medidas normativas. El fantasma hegemónico es la posición [posé] a la cual se relacionan todas las leyes prácticas y cognitivas, es decir, en última instancia, todos los actos y todos los fenómenos (11).

\section{Ontoteología y lógica del gobierno}

Si toda vida es una forma de vida, la lógica ontoteológica de gobierno implica, en primer término, la separación entre vida y forma, y la proyección de la forma como anterior a la vida - de tal manera que la vida no puede tener con su forma otra relación que no sea la obediencia a su régimen de deuda. En segundo término, la lógica ontoteológica de gobierno implica la articulación de la forma de vida en relación a un principio -el fantasma hegemónico como interdicto hermenéutico y normativo, que en griego se expresa en la "relación a lo uno" ( $\pi \rho \rho_{\varsigma}$ हैv), aludido con cierta insistencia por Schürmann.

Habría que pensar con Schürmann el singular, quizás, en conexión con ese "resto" inasimilable (forma-de-vida, uso, en los términos del Agamben de "L'uso dei corpi») que escapa a toda síntesis dialéctica entre opuestos -la dialéctica en

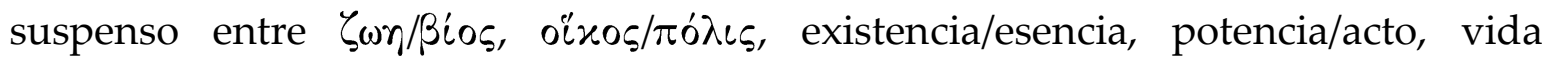
desnuda/poder, violencia/orden, multitud/pueblo, etc. Habría que pensar la potencia de ese "resto" no como algo puro, separado y "anterior" a las oposiciones -pues el resto no resta ni antes ni después de las oposiciones-, sino entre, en tensión destituyente con el propio dispositivo. La potencia como lo que depotencia la potestad del dispositivo y así lo desactiva. A diferencia de Aristóteles -y para pensar no sólo los dispositivos, sino también la facticidad de los procesos de 
subjetivación-, la potencia en sentido ateológico y anárquico no sería así algo anterior a la partición potencia/acto, sino la potencia que resiste como potencia en el acto (Casanova $20167 \mathrm{ss}$ ), "la forma-de-vida que se genera viviendo", no obedeciendo a la representación teleológica del acto, esto es, para decirlo en el

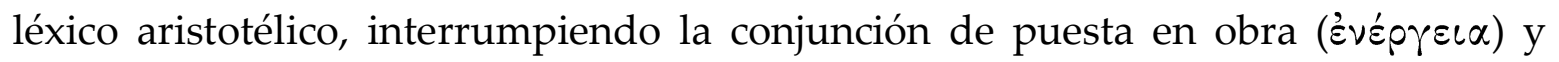
actualización finalizada (

La potencia en un sentido ontológico-modal o expresivo sería, por consiguiente, el uso de los cuerpos y de la potencia común de la imaginación, uso cuya generación se da en una relación destituyente respecto de la metafísica del sujeto (soberanía política, voluntad y comando, imaginación dispositiva, cálculo, etc.). La desactivación de la metafísica del sujeto conllevaría asimismo una relación destituyente respecto de la metafísica de la presencia (gubernamentalidad económica, representación, imagen organizada, idealidad, espectáculo, disposición calculada, etc.) y toda correlativa configuración de una "historicidad maestra" que oriente el movimiento virtuoso del mundo -filosofía de la historia como escenografía evolutivo/sacrificial de "la casa del ser". Se trataría, pues, de un movimiento o dislocación epocal radical desde la estructura arborescente de la ontoteología política (el pros hen o afirmación sacrificial de lo uno como incorporación orgánica bajo un principio trascendental) a la estructura rizomática de la anarquía (afirmación no sacrificial de las multiplicidades inmanentes de lo vivo, proliferación de la vida pagana, de sus éjidos y sus heterocronías). La potencia del viviente como resto habría que pensarla, pues, en tensión destituyente respecto de la ficción imaginal de la trascendencia del poder soberano -el fantasma hegemónico como "trono vacío" o non res- y de su proyección económicogubernamental en la inmanencia como captura, modelamiento, productivización o sacrificio de la vida -tecnología de crianza humanista. Quizás aquí se juega una rica posibilidad de confrontación productiva entre el proyecto de una destrucción fenomenológica de la metafísica (Heidegger, Schürmann) y lo pensable a través de una ontología modal barroca (Benjamin) -pues la "expresión” de la potencia implica la "destrucción" del principio de representación que la captura.

Sin embargo, me parece preciso aquí observar hasta qué punto habría que evitar precipitarse ingenua o cínicamente en una problemática indistinción entre anarquía y nihilismo. Pues habría que distinguir entre la posibilidad que se abre en nuestra época para la anarquía como politicidad no ontoteológica, por una parte, y por otra el nihilismo como consumación/agotamiento de la ontoteología política. Lo que vincula en este registro a la anarquía con el nihilismo, me parece, es lo siguiente: el nihilismo erosiona el texto de la soberanía abriendo la posibilidad de un pensamiento y una política anárquica y aneconómica -“pensar es un privilegio de nuestra época, para la que se vuelve evidente la esencial fragilidad de los 
referentes soberanos", decía Schürmann. La época del nihilismo es la época de la violencia desatada, pues coincide con la crisis de la tradicional forma teológicopolítica de la soberanía: la flexibilidad absoluta o despliegue incontinente del principio de razón suficiente en su forma tecno-capitalista "global" erosiona toda contención estatal $\mathrm{y}$, en su momento crítico, la soberanía dislocada deviene autoafirmación mortífera (necropolítica) de sí misma (cf. Santner 2011) -ya sea en el caso de los monopolios estatales de la violencia "legal" (instrumentalizada por su ensamble con el capital transnacional) o, sólo por dar un ejemplo, en el caso de la violencia sobregirada de los monopolios narcos en la dimensión "ilegal" del capitalismo. En este sentido, Sergio Villalobos-Ruminott ha hablado del "vértigo de la soberanía": en el momento de su crisis/transformación, la soberanía necesita volver a escribir/inscribir su ley en el cuerpo sujeto a la deuda de su régimen. El cuerpo aparece así como el "lienzo donde la misma ley soberana se dibuja y se confirma en un mismo acto": lo que se hace transparente en nuestra época es que la ley no preexiste al cuerpo como un poder definitivamente dado, sino que por su propio desfondamiento necesita inscribirse y reinscribirse permanentemente a través de la violencia en los cuerpos -la excepcionalidad devenida regla (Benjamin). Que la ley se fundamente a sí misma en su violencia quiere decir que performa coyunturalmente "la instanciación de su trascendencia en el orden mundano de una existencia auratizada por la violencia". El universal de la ley se performa permanentemente para poder separarse/purificarse de su opuesto, para ponerse como trascendental por sobre el crimen de la violencia natural: en el cuerpo castigado o aniquilado "coinciden la universalidad de la ley y su excepcionalidad fáctica"13. Lo que la violencia quiere es, precisamente, la particularización ejemplar del singular. De modo que, podríamos decir aquí, el universal de la ley está hecho de contingencia y de una violencia excepcional que tradicionalmente se ha fundamentado metafísicamente en fantasmas hegemónicos como los que analiza destructivamente Schürmann en su trabajo. A la luz de la articulación metafísica de esta violencia habría que considerar, a su vez, el resurgimiento contemporáneo del populismo como pretendido "contramovimiento" a la nihilización capitalista-global, pero que en la práctica no hace sino reafirmar la ontoteología y su humanismo imperial, no cuestionando ni la política del autoritarismo excepcionalista ni la economía de la identidad fuerte del cuerpo social unitario, sea éste étnico, nacional, civilizacional o lo que fuere. Esto se patentiza hoy, con toda su fuerza, por ejemplo, en la configuración expansiva de

\footnotetext{
${ }^{13}$ Me remito aquí a una conferencia de Sergio Villalobos-Ruminott titulada "Los rituales de la carne", pronunciada en las II Jornadas Transdisciplinares de Estudios en Gubernamentalidad, el día 27 de septiembre de 2016 en la Facultad de Ciencias Sociales de la Universidad de Chile, Santiago. Cf., también, Villalobos-Ruminott 201354 ss.
} 
un imaginario político "populista de derechas", en virtud del cual se ha desplazado la frontera política de antagonismo, modificándose la partición amigo/enemigo: el enemigo ya no es "el de arriba" que impone su jerarquía sacrificial y el orden de la explotación en curso, sino "el de afuera" que amenaza la seguridad y la propia identidad de la comunidad pura y disciplinada.

Poder pensar la diferencia entre nihilismo y anarquía, abrir la anarquía en medio del desierto del nihilismo contemporáneo implicaría, quizás, redescubrir la diferencia ontológica (apertura anárquica del abismo del ser), precisamente contra el predominio tradicional de la diferencia ontoteológica (eclipse nihilista del abismo del ser) en la que se ha autoafirmado una política occidental que hoy quisiéramos ya occisa. Se trata en este caso, acaso, tan solo de unos intentos de pensamiento en el ocaso. Pero frente a ello se podrá contraargumentar, desde la pulsión existencial por el fundamento, que la "diferencia ontológica" de Martin Heidegger encubre un anti-humanismo "nihilista", que su rendimiento anárquico disuelve la antropología filosófica como ciencia (cf. Fernández 2008 305-339). Se podrá justificar así la necesidad de ir "más atrás" de Heidegger, para refugiarse de la apertura de su caja de Pandora, para recuperar la noción de subjetividad trascendental aun anclada en la persona de la fenomenología de Edmund Husserl, o la del "fundador" de la antropología filosófica, Max Scheler, que se identifica autoafirmativamente en un sujeto que ocupa un lugar privilegiado en la totalidad del cosmos, aquél en el que se produce la "manifestación" del ser. Eso es lo que se querría para poder seguir siendo "funcionarios públicos de la humanidad" (Husserl), aportando con constancia a la construcción de una antropología filosófica fundamental "a la altura de los tiempos", "para no abandonar el humanismo que ha caracterizado a la filosofía propia de la cultura occidental" (Ibid. 305; cursiva es mía). Tal impugnación sólo mostraría el carácter "trágico" del polemos hermenéutico en el que habitamos, y sería precisamente un signo de la politicidad de la fenomenología. Para terminar, una cita de Agamben, a propósito de la "trampa mortal" de la metafísica política humanista:

Recuerdo que en 1966, mientras frecuentaba en Thor su seminario sobre Heráclito, le pregunté a Heidegger si había leído a Kafka. Me contestó que, de lo no mucho que había leído, había quedado impresionado sobre todo por el relato "La madriguera" ("Der Bau"). El innominado animal (topo, raposo o ser humano) protagonista del relato está obsesivamente preocupado por construir una guarida inexpugnable, que poco a poco resulta ser, por el contrario, una trampa sin salida. Pero, ¿no es precisamente esto lo que ha sucedido en el espacio político de los Estados-nación de Occidente? Las casas ("las patrias") que se han afanado en construir han resultado ser finalmente, para los "pueblos" que debían habitarlas, no otra cosa que trampas mortales (Agamben 2001 116). 


\section{Bibliografía}

Agamben, Giorgio. L'uso dei corpi. Neri Pozza Editori: Vicenza, 2014.

Agamben, Giorgio. Medios sin fin. Notas sobre la política, trad. Antonio Gimeno. Editorial Pre-Textos: Valencia, 2001.

Aristóteles. "Peri; eJrmeneiva », texto griego establecido por Theodor Waitz. Scientia Verlag Aalen: Leipzig, ${ }^{1} 1844$.

Aristóteles. «ïHqikw`n Nikomaceiw`n», edición bilingüe griego-español, trad. María Araujo y Julián Marías. Editorial Centro de Estudios Políticos y Constitucionales: Madrid, 1994.

Casanova, Carlos. Estética y producción en Karl Marx. Editorial Metales Pesados: Santiago de Chile, 2016.

Coccia, Emanuele. La vida de las plantas. Una metafísica de la mixtura, trad. Gabriela Milone. Miño y Dávila Editores: Buenos Aires, 2017.

Díaz Letelier, Gonzalo. “Ontoteología, economía de la presencia y lógica del gobierno: una lectura de Reiner Schürmann”, Revista Política Común 11 (dossier "On Reiner Schürmann", coordinado por Alberto Moreiras) (2017): $\mathrm{s} / \mathrm{p}$.

Díaz Letelier, Gonzalo. "El vuelco en el habitar del hombre arcaico y su declaración mítica en la obra de Hesíodo". Acta Fenomenológica Latinoamericana IV. Pontificia Universidad Católica del Perú/Universidad Autónoma de México: Lima/México, 2012. 553-576.

Didi-Huberman, Georges. Cuando las imágenes tocan lo real, trad. Inés Bértolo, Ediciones Arte y Estética: Madrid, 2007.

Fernández, Pilar. "La posibilidad del humanismo (después de Heidegger)", Anuario Filosófico XLI/2 (2008): 305-339.

Hegel, Georg. Fenomenología del Espíritu, trad. Wenceslao Roces. Editorial F.C.E: México D.F., 1966.

Hegel, Georg. Historia de Jesús, trad. Santiago González Noriega. Editorial Taurus: Madrid, 1981, 
Heidegger, Martin. "Die Onto-Theo-Logische Verfassung der Metaphysik - La constitución onto-teo-lógica de la metafísica". Identität und Differenz Identidad y diferencia, edición bilingüe alemán-español, trad. Helena Cortés y Arturo Leyte. Editorial Anthropos: Barcelona, 1988.

Heidegger, Martin. „Die Frage nach der Technik“. Vorträge und Aufsätze (Teil I). Günther Neske Verlag: Pfullingen, ${ }^{3} 1967$.

Heidegger, Martin. Nietzsche, vol. II, trad. Juan Luis Vermal. Ediciones Destino, Madrid: 2000.

Karmy, Rodrigo. Políticas de la excarnación. Para una genealogía teológica de la biopolítica. Editorial Universitaria UNIPE: Buenos Aires, 2014.

Lagarrigue, Luis. Síntesis Subjetiva, o Sistema Universal de las concepciones propias al Estado Normal de la Humanidad. Industria, bosquejo del Sistema de Industria proyectado por el Supremo Maestro Augusto Comte». Ediciones de la Fundación Juan Enrique Lagarrigue: Santiago, 1946.

Muñoz, Gerardo. "Das Leben ist ohne warum: una nota sobre Reiner Schürmann", en sitio electrónico Machina et Subversio Machinae, entrada del 7 de febrero de 2016: s/p.

Nancy, Jean-Luc. L'Equivalence des catastrophes (Après Fukushima). Editions Galilée: París, 2012.

Nietzsche, Friedrich. La ciencia jovial - La Gaya Scienza, trad. José Jara. Monte Ávila Editores. Caracas, 1985.

Santner, Eric. The royal remains. The people's two bodies and the endgame of sovereignty. The University of Chicago Press: Chicago, 2011.

Schürmann, Reiner. Broken hegemonies, vol. I, traducción del francés al inglés Reginald Lilly. Indiana University Press: Bloomington/Indianapolis, 2003.

Schürmann, Reiner. "Tragic differing: The law of the One and the law of contraries in Parmenides", Graduate Faculty Philosophy Journal 13/ 1 (1988): 3-20.

Schürmann, Reiner. Heidegger on Being and Acting: From Principles to Anarchy, traducido del francés al inglés por Christine Gros. Indiana University Press: Bloomington, 1986. 
Thayer, Willy. "Raúl Ruiz: imagen estilema", Revista de Filosofía Otro Siglo 1/2 (2017): 3-46.

Tönnies, Ferdinand. Gemeinschaft und Gesellschaft. Abhandlung des Communismus und des Socialismus als empirischer Culturformen. Fues's Verlag: Lepzig, 1887.

Villalobos-Ruminott, Sergio. "Teoría crítica de la irreversibilidad", conferencia en el coloquio "Silabario de un futuro irreversible", organizado por el Instituto de Estudios Críticos, Centro Nacional de las Artes, Centro de Cultura Digital, Laboratorio Arte Alameda y Grupo ETC, realizado en México D.F. el 19 de enero de 2018.

Villalobos-Ruminott, Sergio. Soberanías en suspenso. Imaginación y violencia en América Latina. Editorial La Cebra, Buenos Aires: 2013.

Villalobos-Ruminott, Sergio. "Los rituales de la carne", conferencia pronunciada en las II Jornadas Transdisciplinares de Estudios en Gubernamentalidad, en la Facultad de Ciencias Sociales de la Universidad de Chile, Santiago de Chile (27 de septiembre de 2016). 